\title{
Charcot-Marie-Tooth 1A concurrent with anaplastic ependymoma in a toddler: when an acute event unmasks a chronic condition
}

\author{
Maria Gogou, Efterpi Pavlidou, Evangelos Pavlou, Theodotis Papageorgiou, Athanasios \\ Tragiannidis, Andreas Giannopoulos, Emmanuel Hatzipantelis \\ $2^{\text {nd }}$ Department of Pediatrics, School of Medicine, Aristotle University of Thessaloniki, University General Hospital \\ AHEPA, Thessaloniki, Greece. E-mail: mariaangogou@gmail.com
}

Received: 18th July 2018, Revised: 19th August 2018, Accepted: 8th September 2018

\begin{abstract}
SUMMARY: Gogou M, Pavlidou E, Pavlou E, Papageorgiou T, Tragiannidis A, Giannopoulos A, Hatzipantelis E. Charcot-Marie -Tooth 1A concurrent with anaplastic ependymoma in a toddler: when an acute event unmasks a chronic condition. Turk J Pediatr 2019; 61: 428-430.

We report a 14-month-old toddler admitted to the Pediatric Oncology Department after surgical resection of supratentorial anaplastic ependymoma. The child was treated with International Society of Pediatric Oncology Ependymoma II 2015 chemotherapy protocol (vincristine, carboplatin, cisplatin, cyclophosphamide and methotrexate). At the end of the first cycle the child presented with symptoms such as unsteadiness and ataxic gait along with decreased motor and sensory action potentials of the limbs. As the father of the child was diagnosed with Charcot-Marie-Tooth 1A disease, a genetic analysis of the PMP22 gene was performed confirming the diagnosis of CharcotMarie-Tooth $1 \mathrm{~A}$ in the child, too. This case gently reminds the possibility of vincristine-induced neurotoxicity and underscores the significance of an appropriate neurological assessment before vincristine initiation.
\end{abstract}

Key words: Charcot-Marie-Tooth, vincristine, ependymoma, neurotoxicity, neurooncology.

As the number of childhood cancer survivors has significantly increased, the focus of current research has shifted to improving quality of life and preserving the neurodevelopment of these patients. Chemotherapy-induced peripheral neuropathy is a disabling pain condition and a significant source of secondary morbidity. At the same time, adverse pharmaceutical effects can give genesis to phenomena, which may, in turn, reveal challenging underlying pathophysiological links.

\section{Case Report}

We describe a 14-month old female toddler admitted to the Pediatric Oncology Department, after surgical resection of a supratentorial extraventricular mass of the left frontal lobe. Since the age of 12 months, symptoms like intermittent exotropia of the right eye, truncal hypotonia and abnormal increase in head circumference had been noticed. Furthermore, parents describe that the child presented with frequent falls while walking, whereas during the past month her gait was more stable and smoother. Histological examination revealed a grade III anaplastic ependymoma. After surgery significant clinical improvement was noticed and muscle tone, muscle strength and motor skills (including gait pattern) of the child were normal for age. Two months later a $2^{\text {nd }}$ Magnetic Resonance Imaging scan of the brain and the spine cord showed no residual tumor at the resection margins, but hyperintensity related to the lateral ventricles and extending into the genu of the corpus callosum, the brainstem and the surface of the spinal cord and the cauda equina. These findings could be consistent with ependymal tumor infiltration 
and might represent early recurrence. Due to her age, she was ineligible for cranio-spinal radiation. Therefore, chemotherapy was initiated according to the International Society of Pediatric Oncology Ependymoma II 2015 protocol (vincristine, carboplatin, cisplatin, cyclophosphamide and methotrexate). At the end of the first cycle the child presented with "refusal to walk" and "uncoordinated walking pattern". Neurological evaluation revealed ataxic gait and diminished deep tendon reflexes in all limbs, while the remainder of clinical evaluation was normal. A new Magnetic Resonance Imaging scan didn't show any changes in the aforementioned findings. Nerve conduction study revealed decreased motor and sensory action potentials of the limbs. (right median motor nerve conduction velocity: $18,8 \mathrm{~m} / \mathrm{sec}$, right median sensory nerve conduction velocity: $17,5 \mathrm{~m} / \mathrm{sec}$ ). The child's father had been diagnosed during childhood with Charcot-Marie-Tooth 1A due to PMP-22 gene duplication. Given the family history, genetic analysis of the PMP22 gene was requested which revealed PMP22 gene duplication and confirmed Charcot-MarieTooth 1A diagnosis. Symptoms gradually improved, while parents decided to discontinue chemotherapy. The child is currently under regular clinical follow-up undergoing brain imaging every 3 months, while she presents no signs of neurological impairment. An informed consent was received from the family with regards to the presentation of the child's data in this manuscript.

\section{Discussion}

Charcot-Marie-Tooth $1 \mathrm{~A}$ is the most common subtype of Charcot-Marie-Tooth disease, inherited as an autosomal dominant pattern and caused by duplication of the PMP22 gene on chromosome 17 in the vast majority of patients. The PMP22 gene encodes for peripheral myelin protein 22, which is expressed in Schwann cells and is involved in formation and maintenance of compact myelin. Besides, this protein plays a role in interaction of Schwann cells with neuronal axons, while it has also been detected in non-neural tissues where it mainly has a growth-arrest-specific function (cell cycle regulation). ${ }^{2}$

Although a series of chemotherapeutic agents are known to display neurotoxicity, vincristine exhibits a clear relationship with exacerbation of neurological symptoms in patients with Charcot-Marie-Tooth disease of all types. It is noteworthy that in some cases vincristineassociated neurotoxicity led to the diagnosis of underlying asymptomatic Charcot-MarieTooth disease, as it happened in our patient. ${ }^{3}$ In addition, recent literature describes significant genetic associations between vincristineinduced peripheral neuropathies and genes associated with drug absorption, distribution, metabolism, and excretion in patients with leukemia. ${ }^{4}$ Despite this fact, genetic testing for Charcot-Marie-Tooth is not a routine practice before vincristine initiation. Nevertheless, a detailed clinical evaluation and medical history could raise clinical suspicion thus preventing the occurrence of adverse neurological effects

Table I. Literature Examples of Patients with Confirmed Charcot-Marie-Tooth Disease and Solid Tumors.

\begin{tabular}{|c|c|c|c|c|c|c|}
\hline Patient & Age & Gender & Type of tumor & $\begin{array}{l}\text { Diagnosis of } \\
\text { CMT1A prior to } \\
\text { tumor diagnosis }\end{array}$ & $\begin{array}{l}\text { Family history } \\
\text { for CMT1A }\end{array}$ & Outcome \\
\hline $1(\operatorname{Ref} 5)$ & $16 y$ & female & anaplastic medulloblastoma & no & negative & death \\
\hline $2(\operatorname{Ref} 4)$ & $14 y$ & male & $\begin{array}{l}\text { schwannomas of the spinal } \\
\text { cord and the median nerve }\end{array}$ & no & positive & not described \\
\hline $3(\operatorname{Ref} 4)$ & $40 y$ & female & $\begin{array}{l}\text { schwannomas of the } \\
\text { median nerve }\end{array}$ & no & positive & not described \\
\hline $4(\operatorname{Ref} 7)$ & $17 y$ & female & Hodgkin lymphoma & no & negative & $\begin{array}{l}\text { under follow up- } \\
\text { improvement }\end{array}$ \\
\hline $\begin{array}{l}5 \text { (our } \\
\text { patient) }\end{array}$ & $14 \mathrm{~m}$ & female & anaplastic ependymoma & no & positive & under follow up \\
\hline
\end{tabular}

CMT: Charcot-Marie-Tooth 
and permitting alternative treatment options. ${ }^{5}$

An analog of Charcot-Marie-Tooth disease being unmasked after the effect of a trigger factor is reflected in cases of patients with undiagnosed Charcot-Marie-Tooth disease presenting signs and symptoms indicative of Guillain-Barre syndrome. In these patients the past medical history, differentiations between motor and sensory nerve action potential amplitudes, as well as significant improvement without specific medical treatment suggested the underlying diagnosis, which was confirmed with genetic tests. ${ }^{6,7}$

With regards to Charcot-Marie-Tooth disease co-existence with malignancies, we were able to identify in literature case reports describing the co-occurrence of Charcot-Marie-Tooth with Central Nervous System tumors (medulloblastoma, schwannomas), ${ }^{8,9}$ Hodgkin lymphoma, as well as neurofibromatosis type $1 .{ }^{10,11}$ (Table I) The patient described is the first to exhibit co-occurrence of Charcot-MarieTooth disease with this tumor type (anaplastic ependymoma). Amplification of the PMP22 expression has been identified in glioma and osteosarcoma cell lines. ${ }^{12,13}$ Nevertheless, no preclinical or clinical data about the role of the PMP22 in ependymal cells exists. Therefore, no link between ependymoma and PMP22 gene can be drawn or speculated.

In conclusion, this case reminds the need for an appropriate neurological assessment before treatment with specific chemotherapeutic agents. Diagnosis of underlying CharcotMarie-Tooth disease should be considered in case of unexpected neurological deterioration. More extensive reports and further genetic investigations of Charcot-Marie-Tooth disease and malignant conditions may provide a better understanding of their underlying linkage.

\section{REFERENCES}

1. Kandula T, Park SB, Cohn RJ, Krishnan AV, Farrar MA. Pediatric chemotherapy induced peripheral neuropathy: A systematic review of current knowledge. Cancer Treat Rev 2016; 50: 118-128.

2. Li J, Parker B, Martyn C, Natarajan C, Guo J. The PMP22 gene and its related diseases. Mol Neurobiol 2013; 47: 673-698.

3. Chauvenet AR, Shashi V, Selsky C, Morgan E, Kurtzberg J, Bell B; Pediatric Oncology Group Study. Vincristine-induced neuropathy as the initial presentation of charcot-marie-tooth disease in acute lymphoblastic leukemia: a Pediatric Oncology Group study. J Pediatr Hematol Oncol 2003; 25: 316-320.

4. Wright GEB, Amstutz U, Drögemöller BI, et al; Canadian Pharmacogenomics Network for Drug Safety Consortium. Pharmacogenomics of vincristine-induced peripheral neuropathy implicates pharmacokinetic and inherited neuropathy Genes. Clin Pharmacol Ther 2019; 105: 402-410.

5. Ichikawa M, Suzuki D, Inamoto J, et al. Successful alternative treatment containing vindesine for acute lymphoblastic leukemia with Charcot-Marie-Tooth disease. J Pediatr Hematol Oncol 2012; 34: 239-241.

6. Parissis D, Ioannidis P, Papadopoulos G, Karacostas D. Charcot-Marie-Tooth disease $1 \mathrm{X}$ simulating paraparetic Guillain-Barre syndrome. Neurologist 2017; 22: 234-236.

7. Odaka M, Yuki N, Kokubun N, Hirata K, Kuwabara S. Axonal Guillain-Barré syndrome associated with axonal Charcot-Marie-Tooth disease. J Neurol Sci 2003; 211: 93-97.

8. Kwon JY, Chung KW, Park EK, Park SW, Choi BO. Charcot-Marie-Tooth 1A concurrent with schwannomas of the spinal cord and median nerve. J Korean Med Sci 2009; 24: 763-766.

9. Aghajan Y, Yoon JM, Crawford JR. Severe vincristineinduced polyneuropathy in a teenager with anaplastic medulloblastoma and undiagnosed Charcot-MarieTooth disease. BMJ Case Rep 2017; doi: 10.1136/bcr2016-218981.

10. Koc F, Guzel AI. Neurofibromatosis type 1 associated with Charcot-Marie-Tooth type 1A. J Dermatol 2009; 36: 306-311.

11. Cil T, Altintas A, Tamam Y, Battaloğlu E, Isikdogan A. Low dose vincristine-induced severe polyneuropathy in a Hodgkin lymphoma patient: a case report (vincristine-induced severe polyneuropathy). J Pediatr Hematol Oncol 2009; 31: 787-789.

12. Liu $S$, Chen $Z$. The functional role of PMP22 gene in the proliferation and invasion of osteosarcoma. Med Sci Monit 2015; 21: 1976-1982.

13. Hühne K, Park O, Liehr T, Rautenstrauss B. Expression analysis of the PMP22 gene in glioma and osteogenic sarcoma cell lines. J Neurosci Res 1999; 58: 624-631. 